\title{
BMJ Open Correlation of patient complexity with the burden for health-related professions, and differences in the burden between the professions at a Japanese regional hospital: a prospective cohort study
}

Shuhei Yoshida, ${ }^{1,2,3}$ Masato Matsushima, ${ }^{1}$ Hidetaka Wakabayashi, ${ }^{4}$ Rieko Mutai, ${ }^{1}$ Yoshifumi Sugiyama, ${ }^{1,5}$ Toshifumi Yodoshi, ${ }^{1}$ Ryoko Horiguchi, ${ }^{1}$ Takamasa Watanabe, ${ }^{1,2}$ Yasuki Fujinuma ${ }^{2,6}$

To cite: Yoshida S, Matsushima M, Wakabayashi $\mathrm{H}$, et al. Correlation of patient complexity with the burden for health-related professions, and differences in the burden between the professions at a Japanese regional hospital: a prospective cohort study. BMJ Open 2019;9:e025176. doi:10.1136/ bmjopen-2018-025176

- Prepublication history for this paper is available online. To view these files, please visit the journal online (http://dx.doi. org/10.1136/bmjopen-2018025176).

Received 3 July 2018 Revised 20 December 2018 Accepted 27 December 2018

D) Check for updates

(c) Author(s) (or their employer(s)) 2019. Re-use permitted under CC BY-NC. No commercial re-use. See rights and permissions. Published by BMJ.

For numbered affiliations see end of article.

\section{Correspondence to}

Dr Shuhei Yoshida;

yoshida.shuhei.0810@gmail. com

\section{ABSTRACT}

Objectives An ageing society includes high patient complexity. Various biopsychosocial problems result in a high burden for health-related professionals. The direct relationship between the burden and patient complexity, however, has not been reported. We aimed to examine correlations between the burden for the attending physicians and nurses, and Patient Centred Assessment Method (PCAM) scores of patient complexity.

Design Prospective cohort study.

Setting A regional secondary care hospital in Japan. Participants We included all inpatients admitted to our acute care unit between 1 July 2014 and 30 September 2014. Exclusion criteria were age $<20$ years, refusal to participate in the study and length of stay fixed at the time of admission.

Main predictor PCAM total score in the initial phase of hospital admission.

Main outcome The burden for each profession (measured on a Visual Analogue Scale).

Results In total, 201 inpatients participated [female/ male=98/103, mean (SD) age of $77.4 \pm 11.9$ years]. Spearman's rank correlation coefficients between the burden and the PCAM score ranged from 0.23 to 0.32 . All $p$ values were $<0.05$. Multivariate analysis was conducted using multilevel mixed-effects linear regression to determine the association between the burden and the PCAM score in two models. Model 1 used the total PCAM score as the predictive variable. Model 2 used the PCAM factors, patient-oriented complexity and medicine-oriented complexity, as predictive variables. In Model 2, with the burden of physicians, medicine-oriented complexity was statistically significant, whereas with the burden of nurses, both age and patient-oriented complexity were statistically significant.

Conclusions PCAM scores correlated with the burden for physicians and nurses. Individual PCAM factors affected the burden for each profession differently.
Strengths and limitations of this study

- This study evaluated the burden from an individual patient, not the burden from the whole work.

- Because evaluator of the Patient Centred Assessment Method (PCAM) did not engage in patient care, the score was objectively judged.

- According to the analysis by the detected and labelled two factors, the interpretation of the difference between the physicians and nurses could be concrete.

- Neither the inter-rater variability in the PCAM scores nor the spectrum of diseases on admission to community-based hospitals was taken into account in the analysis.

- Although the suitability of using a Visual AnalogueScale for evaluating the perception of burden was uncertain, this measure was practical to administer.

\section{INTRODUCTION}

An ageing society gives rise to various health problems with biopsychosocial aspects which health-related professionals must resolve. ${ }^{1}$ Many patient outcomes for a variety of complaints-such as low back pain, alcohol misuse and chronic pain-are affected by various biopsychosocial problems. ${ }^{2-5}$ These studies also showed that the introduction of the biopsychosocial model led to a more effective management of these problems. ${ }^{2-4}$ The comprehensive evaluation of biopsychosocial problems is important in clinical practice. $^{6}$

We have used the concept of patient complexity to evaluate various biopsychosocial problems. ${ }^{7}$ The word 'complexity' was 
used by Osborn and Cole instead of referring to difficult patients, believing that medical students and residents can acquire the necessary skills to assess areas of complexity. ${ }^{8}$ Difficult patients are defined as those who elicit strong negative emotions from their physicians. ${ }^{9}$ Typical characteristics of difficult patients include depressive or anxiety disorders, a greater number of somatic symptoms and greater symptom severity. ${ }^{10}$ Many biopsychosocial factors of difficult patients have been examined, including multiple medical issues, psychiatric diagnoses, low literacy and financial constraints. ${ }^{11}$ Several instruments to measure patient complexity have been developed as a result of this concept-for instance, INTERMED, the Minnesota Complexity Assessment Method and the Patient Centred Assessment Method (PCAM). ${ }^{12-14}$ The PCAM-an advanced version of the Minnesota Complexity Assessment Method developed in Scotland-is a practical tool for use in the primary care setting. We examined, in a Japanese secondary care setting, the validity and reliability of the PCAM and the relationship between PCAM and the length of hospital stay. ${ }^{15}$ We found that health problems needing concrete intervention were detectable using this method.

In general, health-related professionals carry the burden resulting from difficult patients, suffering, in consequence, from 'burn-out', depression and so on. ${ }^{16}$ Studies have suggested that various factors affect the burden among health-related professionals, especially physicians and nurses, ${ }^{17-20}$ and that there were differences in the burden between physicians and nurses in the same situation. ${ }^{21}$ According to this study, when new decisions about the various problems were needed, the physicians and nurses tended to feel the burden. However, the types of problems were different from the biopsychosocial aspects. The PCAM contains these elements as items for evaluating patient complexity. Therefore, the results of PCAM evaluations could represent the degree of difficulty inherent in treating each patient. It is, however, unknown whether the simple addition of PCAM score for each item to provide a total score is meaningful in a clinical setting. As yet, there have been no reports on the direct relationship between these items.

If it were possible to estimate the likely burden from patients at the start of care through evaluation using the PCAM, it might be possible to implement counter measures. The aim of our study was to evaluate the relationship between the total PCAM score on admission and the burden for health-related professionals, specifically physicians and nurses. In addition, we hoped, by evaluating the PCAM items, to detect the area in which each health-related profession felt the burden. An understanding of the existence of differences in the respective burdens for physicians and nurses could lead to improved mutual understanding. By investigating whether problems that can be anticipated from PCAM scores are related to outcomes in clinical practice, this study provides basic information for future studies on how to intervene in those problems.

\section{METHODS}

\section{Study group and setting}

We performed this prospective cohort study along with a study investigating the validity and reliability of the PCAM. ${ }^{15}$ As is the case with the validation study, we adopted all inpatients admitted to the acute care unit of Ouji Coop Hospital between 1 July 2014 and 30 September 2014 as our participants. Because there had been no report on PCAM at the time of planning this study, we were not able to calculate an accurate required sample size. Instead, we set the study period to be 3 months, estimating that the total number of patients would be about 300 because the average number of admission in a month was 100. Kita$\mathrm{ku}$, Tokyo, Japan, is a district with a high population-ageing-rate and served by Ouji Coop Hospital, a regional secondary care hospital and family physician teaching facility with 159 beds. Our hospital has no surgical facilities; patients needing surgical treatment are referred to other hospitals. During the study period, most inpatients were admitted to treat the following medical conditions: pneumonia, urinary tract infection, acute exacerbation of chronic illness (chronic obstructive pulmonary disease, diabetes), dermatological conditions such as decubitus ulcers and cellulitis, orthopaedic conditions such as lumbar compression and proximal femoral fractures that do not require surgery and cancer pain not being controlled in ambulatory or home medical care. ${ }^{15}$ Exclusion criteria were age below 20 years, refusal to participate in the study and length of stay fixed at the time of admission such as in colonic poplypectomy and gastric fistula exchange. No patient was excluded by the age criterion.

\section{Measurement variables and evaluation process}

The outcome measure was the burden perceived by physicians and nurses from each patient, measured by a Visual Analogue Scale (VAS). After the discharge of each patient, one of the authors (S.Y.) requested that the attending physician and nurse respond to the questionnaire within 1 week. S.Y. was not involved in the care of these patients. This questionnaire contained one question in Japanese language- 'Please tell us the burden you perceived from this patient during hospitalisation.' We subsequently distributed the VAS using this question. The length of the VAS was not exactly equal to $100 \mathrm{~mm}$ once printed out. The length from 0 to the marked point was divided by the total line length. The notation of this result ranged from $0 \%$ to $100 \%$, and two independent evaluators, with no connection to either the health-related profession or the authors, calculated the VAS score. We adopted the mean of each VAS score for use in statistical analysis.

\section{Predictor variables and covariates}

Complexity scales

When one of the authors was independent from other physicians, he evaluated the PCAM by interviewing patients and patients' family members. Given that the PCAM was not available in Japanese, the interviewer translated and asked the questions in Japanese. The 
interviewer, after judging the items on the PCAM, completed the assessment, bearing in mind the Japanese context and was able to employ the appropriate questions for each item from the sample questions included in the PCAM guide when translating into Japanese. For ethical reasons, we informed members of the staff who worked in the hospital and were involved in the care of the patients that they could have access to the results of these complexity scores if they wished; however, no one requested these results during the research period.

\section{PCAM}

The PCAM is a tool designed for action-based evaluation of complexity in primary care settings, developed by Pratt $e t$ al from the Minnesota Complexity Assessment Method. ${ }^{14}$ Intended for use in patients with comorbid conditions or multimorbidity, it evaluates patients' centredness in addition to their experience. Yoshida et al examined the validity and reliability of the PCAM and the relationship between the PCAM and the length of hospital stay in a Japanese secondary care setting. ${ }^{15}$ The PCAM comprises 12 items in four domains: 'Health and Well-being' (four items), 'Social Environment' (four items), 'Health Literacy and Communication' (two items) and 'Service Coordination' (two items). Each item is scored from 1 to 4 points, with the highest possible score of 48 . Higher scores indicate greater patient complexity.

In a previous study, we used exploratory factor analysis and showed that the 12 PCAM items could be divided into two factors which we named patient-oriented complexity (the patient's internal factors, such as mental condition and literacy) and medicine-oriented complexity (external factors such as the care environment and service). ${ }^{15}$ Patient-oriented complexity comprised items 2, 3 and 4 from the Health and Well-being domain, 2 and 3 from Social Environment and 1 and 2 from Health Literacy and Communication. Of these, the items with the highest and second highest factor loadings were Health Literacy and Communication item 1: 'How well does the client now understand their health and well-being (symptoms, signs or risk factors) and what they need to do to manage their health?' and Health Literacy and Communication item 2: 'How well do you think your client can engage in healthcare discussions? (Barriers include language, deafness, aphasia, alcohol or drug problems, learning difficulties and concentration)' (cited from PCAM online) ${ }^{22}$ Medicine-oriented complexity comprised item 1 from Health and Well-being, 1 and 4 from Social Environment and 1 and 2 from Service Coordination. Of these, the items with the highest and second highest factor loading were Service Coordination item 1: 'Do other services need to be involved to help this client?' and Service Coordination item 2: 'Are services involved with this client well coordinated?'. ${ }^{22}$

\section{Participants' characteristics}

We obtained age, sex, number of medications, length of hospital stay and discharge destination from electronic medical records. ${ }^{23}$ Ancillary staff members, who administered the Charlson Comorbidity Index (CCI) and Mini Nutritional Assessment-Short Form (MNA-SF)], also asked patients or family members about the number of family members living with the patients, whether they had a principal caregiver, and whether they had received public assistance. ${ }^{24-27}$

\section{CCI}

Developed in 1987, the CCI evaluates comorbidities by allocating scores to 16 medical conditions. ${ }^{24}$ Most conditions are given scores of either 1 point or 2 points, although moderate-to-severe liver disease receives 3 points, and metastatic solid tumours and AIDS receive 6 points. The individual scores are summed to give a single overall score. A study in 2014 of elderly patients admitted to acute hospitals reported that the CCI score on admission correlated with subsequent mortality. ${ }^{25}$ The study showed that, compared with patients with a CCI of 0 , those with a CCI of $\geq 5$ had much higher 3-month, 1-year and 5-year mortality (with OR of about 3.5, 7 and 52 , respectively).

\section{MNA-SF}

We assessed the nutritional status using the MNA-SF, which comprises six questions covering declining food intake, recent weight loss, mobility, recent psychological stress or an acute disease, neuropsychological problems and either body mass index or a calf circumference measurement. ${ }^{26-28}$ Each question is scored from 0 to 2 or 0 to 3 , with lower scores representing a greater risk of malnutrition. The highest possible score is 14 . The overall score is interpreted as follows: 12-14 points - 'normal nutritional status', 8-11 points - 'at risk of malnutrition' and 0-7 points - 'malnourished'. A study in a Japanese community hospital confirmed that MNA-SF score was a predictor of health-related outcomes. ${ }^{29}$

\section{Analysis and statistical methods}

The correlation between the burdens for the physicians and nurses and that between the PCAM scores and the burden were calculated using Spearman's rank correlation coefficient after establishing these data were non-parametric using the Shapiro-Wilk test.

Multivariate analysis using multilevel mixed-effects linear regression was performed to investigate the association between the burden for health-related staff and the PCAM. The evaluators for the burden were included in the model as a random effect and patient-level covariates were included as fixed effects. We chose the covariates through a literature review and discussion, taking into consideration important aspects of the Japanese clinical setting. ${ }^{15}$ 28-31 The chosen covariates were comorbidity, nutritional status, polypharmacy, length of hospital stay and discharge destination, in addition to basic information such as sex and age. Two models were developed. In Model 1, the predictive variable was the total PCAM score and the covariates were age, sex, MNA-SF score, CCI score, 
total number of medications, length of hospital stay and discharge destination. In Model 2, the predictive variables were the two factors of the PCAM and the covariates were age, sex, MNA-SF score, CCI score, total number of medications, length of hospital stay and discharge destination. The scores of total PCAM and each factor were centred around the evaluator mean (centring within cluster). To check for multicollinearity, we calculated the correlations between predictors using the pairwise Pearson's correlation coefficient and variance inflation factors.

We performed all statistical analyses using STATA/SE V.14 (StataCorp, 2017). In the multivariate analysis, we considered $\mathrm{p}<0.025$ to be statistically significant: each PCAM item and two factors of the PCAM were examined twice with multivariate analysis. In other cases, we considered $p<0.05$ to be statistically significant.

\section{Patient and public involvement}

No patient or member of the public was involved in developing the research question or outcome measures or in developing plans for the study design or implementation of the study. We intend to disclose and summarise the results of this study on the homepage of our website (Department of Community-Based Medical System, Graduate School of Biomedical and Health Sciences, Hiroshima University). ${ }^{32}$

\section{RESULTS}

\section{Participant characteristics on admission}

As was the case with the validation study, among 263 admissions, 46 patients met the exclusion criteria: one person refused to participate in the study and on admission, 45 patients had a pre-determined, fixed length of hospital stay. In addition, owing to cognitive impairment, two patients could not be interviewed and there was no possibility of interviewing their families; four individuals were immediately referred to other hospitals for emergency operations; 10 patients had no score for the MNA-SF owing to missing values. Thus, 201 inpatients participated in this study. Their characteristics are shown in table 1.

The mean (SD) PCAM score was $25 \pm 7.3$. The participants (and their characteristics) were the same as in the previous validation study; details of the participants' main diseases can be found in the report to that study. ${ }^{15}$

\section{The burden evaluators' characteristics}

The characteristics of the attending physicians and nurses who responded to the question about the burden are presented in table 2.

The correlation of the burden between the attending physician and the attending nurse

Responses to the questionnaire were received for $84 \%$ $(169 / 201)$ of the patients from the attending physicians and for $98.5 \%(198 / 201)$ of the patients from the attending nurses. Figure 1 shows the distribution of the
Table 1 Participants' characteristics at admission

\begin{tabular}{|c|c|}
\hline Age: years, mean (SD) & $77.4(11.9)$ \\
\hline Female, n (\%) & $98(48.8)$ \\
\hline Number of medications: mean (SD) & $6.4(4.1)$ \\
\hline Cancer, n (\%) & 36 (17.9) \\
\hline Diabetes mellitus, n (\%) & $44(21.9)$ \\
\hline Receiving public assistance, n (\%) & 38 (18.9) \\
\hline $\begin{array}{l}\text { Charlson Comorbidity Index score, } \\
\text { mean (SD) }\end{array}$ & $2.0(2.2)$ \\
\hline $\begin{array}{l}\text { Mini Nutritional Assessment-Short } \\
\text { Form score, mean (SD) }\end{array}$ & $7.9(3.8)$ \\
\hline Length of stay (days), mean (SD) & $34.1(40.9)$ \\
\hline \multicolumn{2}{|l|}{ Number of family members, $\mathrm{n}(\%)$} \\
\hline 0 & $66(32.8)$ \\
\hline 1 & $83(41.3)$ \\
\hline 2 & $31(15.4)$ \\
\hline$\geq 3$ & $21(10.5)$ \\
\hline Not married, n (\%) & $35(17.4)$ \\
\hline \multicolumn{2}{|l|}{ Principal caregiver, n (\%) } \\
\hline None & $45(22.4)$ \\
\hline Husband or wife & $62(39.0)$ \\
\hline Son or daughter & $75(47.1)$ \\
\hline Female & 99 (62.3) \\
\hline \multicolumn{2}{|l|}{ Discharge destination, n (\%) } \\
\hline Home & $148(73.6)$ \\
\hline Nursing home & $19(9.4)$ \\
\hline Other hospital & $33(16.4)$ \\
\hline Others & $1(0.6)$ \\
\hline
\end{tabular}

VAS. Each attending physician and nurse drew a line on the VAS scale as their perception of the burden from patients. The physicians answered the questionnaire for 169 participants and the mean (SD) of the VAS was $41.4 \pm 22.4(\%)$. The nurses answered the questionnaire for 198 participants and the mean (SD) of the VAS was $60.7 \pm 20.8(\%)$. Figure 2 shows the correlation between the VAS of the physicians and that of the nurses. Spearman's rank correlation coefficient was 0.28.

Table 3 shows the correlation between the PCAM and the burden and between each PCAM factor and the burden. The range of Spearman's rank correlation coefficient was from 0.23 to 0.32 . All $p$ values are $<0.05$.

Table 4 shows the results, after adjusting the covariates, of the multivariate linear regression analysis examining the associations between the total PCAM score and the burden and between each PCAM factor and the burden. In Model 1, we found both age and the total score of the PCAM to be statistically significant, both for physicians and for nurses. In Model 2, we found age and medicine-oriented complexity to be statistically significant for the burden for physicians. In contrast, we found age and patient-oriented complexity to be statistically significant 


$\begin{array}{ll}\text { Table } 2 \text { Characteristics of the burden evaluators } \\ \begin{array}{l}\text { Physicians } \\ \text { Number of physicians: } \mathrm{n}\end{array} \\ \begin{array}{l}\text { Age: years, mean (SD) } \\ \text { Female, } \mathrm{n}(\%)\end{array} \\ \begin{array}{l}\text { Years of working experience, mean (SD) } \\ \text { Nurses }\end{array} \\ \begin{array}{l}\text { Number of nurses, } \mathrm{n} \\ \text { Age: years, mean (SD) }\end{array} \\ \begin{array}{l}\text { Female, } \mathrm{n}(\%) \\ \text { Years of working experience, mean (SD) }\end{array} & 23 \\ \end{array}$

for the burden for nurses. We examined variance inflation factors to ascertain whether there was multicollinearity among predictor variables. Since the variance inflation factors of each variable in our two models ranged between 1.05 and 1.43 , we were able to rule out the existence of multicollinearity.

\section{DISCUSSION}

Our study revealed a relationship between patient complexity at admission and the burden for physicians and nurses. We also discovered the potential of different factors of patient complexity to exert an effect on the perception regarding burden by each health-related professional.

In Model 1, we found a statistically significant correlation between the total score of the PCAM at admission and the burden perceived by physicians and nurses. A high PCAM total score indicates high patient care complexity, which might be expected to result in a high burden for health-related professionals. The accumulation of factors relating to encounters with difficult patients increased the physicians' and nurses' burden. Through the evaluation of PCAM scores at admission, we were able estimate

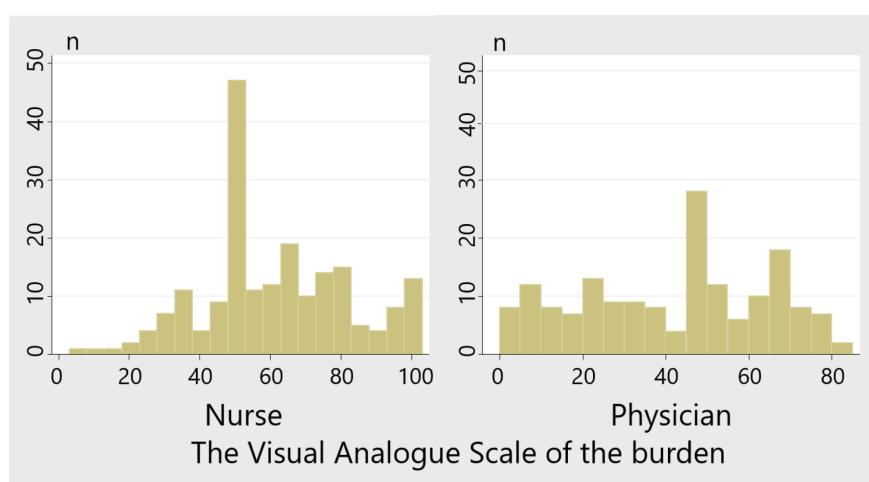

Figure 1 The distribution of Visual Analogue Scale (VAS) of the burden The physicians answered the questionnaire for 169 participants and the mean (SD) of the VAS was $41.4 \pm 22.4$ (\%). The nurses answered the questionnaire for 198 participants and the mean (SD) of the VAS was $60.7 \pm 20.8$ (\%).

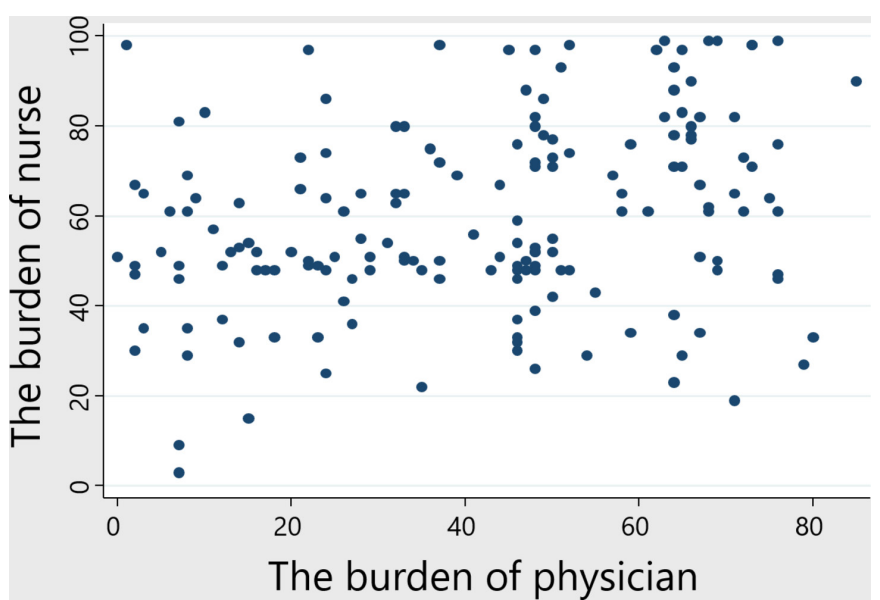

Figure 2 Visual Analogue Scale of the burden between physician and nurse Spearman's rank correlation coefficient was 0.28 .

the burden for health-related professionals evaluated at the time of discharge.

Using Spearman's rank correlation coefficients, we found a weak correlation between the physicians' burden and nurses' burden. Furthermore, in Model 2, we found a correlation between patient-oriented complexity and the burden for nurses, but not for physicians. Similarly, in Model 2, we found a correlation between medicine-oriented complexity and the burden for physicians, but not for nurses. Given that patient-oriented complexity relates to patients' internal factors, such as their mental condition and literacy, and medicine-oriented complexity relates to external factors, such as the care environment and service, the health-related professionals recognised different types of health problems as difficult. Previous qualitative research has revealed differences in burden between physicians and nurses. ${ }^{33}$ Another study highlighted the differences between the views of nurses and those of physicians concerning communication. ${ }^{35}$ Such differences can result from various factors. One factor would be how each profession views its role. Physicians see their role as medical plan managers, decision-makers or coordinators who oversee all aspects of the patient's care. ${ }^{19}$ Conversely, nurses see their role as compassionate

Table 3 Univariate analysis: the correlation between the Patient Centred Assessment Method (PCAM) scores and the burden

\begin{tabular}{llllll}
\hline & \multicolumn{3}{l}{$\begin{array}{l}\text { Visual Analogue Scale scores for } \\
\text { the burden }\end{array}$} \\
\cline { 2 - 3 } & \multicolumn{2}{l}{ Nurse } & & & \multicolumn{2}{l}{ Physician } \\
\cline { 2 - 3 } \cline { 5 - 6 } & $\rho$ & P value & & $\rho$ & P value \\
\hline PCAM & 0.29 & $<0.001$ & & 0.29 & $<0.001$ \\
$\begin{array}{l}\text { Patient-oriented } \\
\text { complexity }\end{array}$ & 0.31 & $<0.001$ & & 0.23 & 0.003 \\
$\begin{array}{l}\text { Medicine-oriented } \\
\text { complexity }\end{array}$ & 0.23 & 0.003 & 0.32 & $<0.001$ \\
\hline
\end{tabular}


Table 4 Multivariate analysis: correlation between Patient Centred Assessment Method (PCAM) scores and the burden

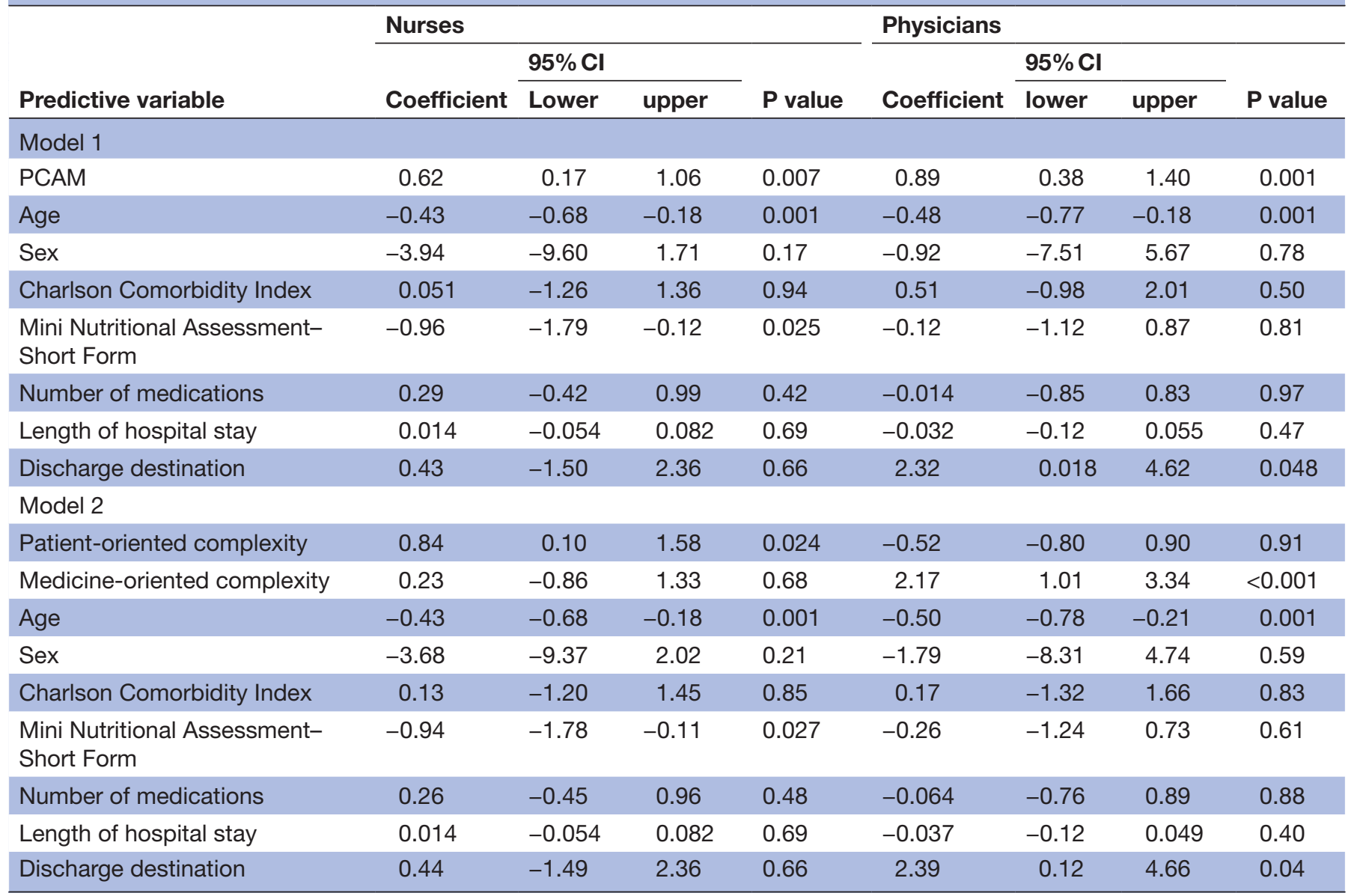

care providers who administer medication, take care of all of the patients' needs, follow physicians' orders and sometimes question those orders. ${ }^{19}$ These different perceptions of roles may have resulted in the two professions associating a different level of burden with the two types of complexity (patient-oriented and medicine-oriented). Different professional and education systems may also have affected these results. ${ }^{36-38}$ This realisation could serve to improve communication between physicians and nurses.

Our study had some limitations. Only one researcher evaluated the PCAM scores, whereas in clinical situations, this task would be performed by various care providers. Neither the inter-rater variability of the PCAM scores nor the spectrum of diseases at admission to community-based hospitals was taken into account. The PCAM scores may also have been affected by differences in care setting, type and severity of disease, insurance systems and other factors. In addition, the outcome measure was a self-reported VAS. The length of the VAS line was not exactly equal to $100 \mathrm{~mm}$ after printing. The results of the VAS score were therefore calculated by division. The suitability of the VAS for calculating the perception of burden was uncertain. However, no other valid and reliable tool would have sufficed for the aim of this study. In addition, patient and public involvement was not considered while planning and conducting this research, as is the case with many other Japanese studies.

The problems revealed in this study provided an initial evaluation for a start to the next steps. The findings of this study provide basic information for interventions in those problems in future studies. With this objective in mind, we plan to develop a Japanese version of PCAM to facilitate its widespread use as a complexity assessment tool in Japan. We also intend to examine and explore the availability of PCAM to address the problems revealed in this study.

\section{CONCLUSION}

Our findings indicate that the PCAM correlates with the burden for two medical professions: physicians and nurses. Moreover, different factors exist among each profession in the way in which they perceive these burdens.

Author affiliations

${ }^{1}$ Division of Clinical Epidemiology, Research Center for Medical Sciences, The Jikei University School of Medicine, Tokyo, Japan

${ }^{2}$ Centre for Family Medicine Development, Japanese Health and Welfare Cooperative, Tokyo, Japan

${ }^{3}$ Department of Community-Based Medical System, Graduate School of Biomedical and Health Sciences, Hiroshima University, Hiroshima, Japan 
${ }^{4}$ Department of Rehabilitation Medicine, Yokohama City University Medical Center, Yokohama, Japan

${ }^{5}$ Tarama Clinic, Okinawa Miyako Hospital, Miyakojima, Japan

${ }^{6}$ Interprofessional Education Research Center (IPERC), Chiba University, Chiba, Japan

Acknowledgements The authors would like to thank Rebekah Pratt at the Department of Family Medicine and Community Health, University of Minnesota, for allowing the use of PCAM.

Contributors SY reviewed and edited the manuscript, conducted the research study and was primarily responsible for data collection, integrity, and analysis. MM reviewed and edited the manuscript and was primarily responsible for data collection, integrity, and analysis. HW, RM, YS, TY, RH, TW and YF reviewed and edited the manuscript, contributed to the discussion of the data and performed critical review of the manuscript. All authors contributed the conception of this work. All authors revised it critically for important intellectual content. All authors approved the final version for publication. All authors agree to be accountable for all aspects of the work

Funding This study was supported by a grant for postgraduate students from The Jikei University School of Medicine. The study sponsor had no role in the study design, data collection, analysis and interpretation, writing the report, or the decision to submit the article for publication.

Competing interests SY worked at Ouji Coop Hospital. YF and TW work as part-time physicians at Ouji Coop Hospital. MM is an adviser of Centre for Family Medicine Development practice-based research network. MM received lecture fee and travel fee for lecture from Centre for Family Medicine Development. MM received the grant from Japan Society for the Promotion of Science. SY and TW were former residents in family medicine at the Centre for Family Medicine Development. MM is a Program Director for Jikei Clinical Research Program of Primary-care. YF is a lecturer of Jikei Clinical Research Program for Primary-care. YS is a trainee of Jikei Clinical Research Program for Primary-care. SY, HW, TY and TW were former trainees of Jikei Clinical Research Program for Primarycare. This work was supported by a research grant of fiscal year 2015 from The Jikei University School of Medicine and Postgraduate Medical School. There is no potential competing interest to be declared relevant to this work other than the above description

\section{Patient consent Obtained.}

Ethics approval The Ethics Committee at Tokyo Hokuto Health Co-operative approved the present protocol. The approval number was 70 .

Provenance and peer review Not commissioned; externally peer reviewed.

Data sharing statement Data sharing is not applicable to this article as no datasets were generated or analysed during the current study.

Open access This is an open access article distributed in accordance with the Creative Commons Attribution Non Commercial (CC BY-NC 4.0) license, which permits others to distribute, remix, adapt, build upon this work non-commercially, and license their derivative works on different terms, provided the original work is properly cited, appropriate credit is given, any changes made indicated, and the use is non-commercial. See: http://creativecommons.org/licenses/by-nc/4.0/.

\section{REFERENCES}

1. Dziechciaż M, Filip R. Biological psychological and social determinants of old age: bio-psycho-social aspects of human aging. Ann Agric Environ Med 2014;21:835-8.

2. Waddell G. Biopsychosocial analysis of low back pain. Baillieres Clin Rheumatol 1992;6:523-57.

3. Chermack ST, Giancola PR. The relation between alcohol and aggression: an integrated biopsychosocial conceptualization. Clin Psychol Rev 1997;17:621-49.

4. Turk DC, Monarch ES. Biopsychosocial perspective on chronic pain. Psychological approaches to pain management: A practitioner's handbook 1996:3-32.

5. Marin TJ, Van Eerd D, Irvin E, et al. Multidisciplinary biopsychosocial rehabilitation for subacute low back pain. Cochrane Database Syst Rev 2017;6:Cd002193.

6. Borrell-Carrió F, Suchman AL, Epstein RM. The biopsychosocial model 25 years later: principles, practice, and scientific inquiry. Ann Fam Med 2004;2:576-82.
7. Peek CJ, Baird MA, Coleman E. Primary care for patient complexity, not only disease. Fam Syst Health 2009;27:287-302.

8. Osborn J, Cole A. Teaching About Patients With Complexity. http:// www.stfm.org/NewsJournals/EducationColumns/Jan2014 (Accessed 31 Oct 2018)

9. Ovens H. Part I: the difficult patient: medical and legal approaches. Can Fam Physician 1989;35:1797-802.

10. Jackson JL, Kroenke K. Difficult patient encounters in the ambulatory clinic: clinical predictors and outcomes. Arch Intern Med 1999:159:1069-75.

11. Cannarella Lorenzetti $\mathrm{R}$, Jacques $\mathrm{CH}$, Donovan $\mathrm{C}$, et al. Managing difficult encounters: understanding physician, patient, and situational factors. Am Fam Physician 2013;87:419-25.

12. Huyse FJ, Lyons JS, Stiefel FC, et al. "INTERMED": a method to assess health service needs. I. Development and reliability. Gen Hosp Psychiatry 1999;21:39-48.

13. Stiefel FC, de Jonge P, Huyse FJ, et al. "INTERMED": a method to assess health service needs. II. Results on its validity and clinical use. Gen Hosp Psychiatry 1999;21:49-56.

14. Pratt $R$, Hibberd C, Cameron IM, et al. The Patient centered assessment method (PCAM): integrating the social dimensions of health into primary care. $J$ Comorb 2015;5:110-9.

15. Yoshida S, Matsushima M, Wakabayashi $\mathrm{H}$, et al. Validity and reliability of the Patient Centred Assessment Method for patient complexity and relationship with hospital length of stay: a prospective cohort study. BMJ Open 2017;7:e016175.

16. Simon JR, Dwyer J, Goldfrank LR. The difficult patient. Emerg Med Clin North Am 1999;17:353-70.

17. Loeb DF, Binswanger IA, Candrian C, et al. Primary care physician insights into a typology of the complex patient in primary care. Ann Fam Med 2015:13:451-5.

18. Brown SS, Lindell DF, Dolansky MA, et al. Nurses' professional values and attitudes toward collaboration with physicians. Nurs Ethics 2015;22:205-16.

19. Lancaster G, Kolakowsky-Hayner S, Kovacich J, et al. Interdisciplinary communication and collaboration among physicians, nurses, and unlicensed assistive personnel. J Nurs Scholarsh 2015;47:275-84.

20. Caricati L, Mancini T, Sollami A, et al. The role of professional and team commitments in nurse-physician collaboration. J Nurs Manag 2016;24:E192-200.

21. Ziegler S, Merker H, Schmid M, et al. The impact of the inpatient practice of continuous deep sedation until death on healthcare professionals' emotional well-being: a systematic review. BMC Palliat Care 2017;16:30.

22. Patient Centered Assessment Method [PCAM] Online: bringing the social determinants of health into primary care. http://www. pcamonline.org/ (cited 31 Oct 2018).

23. Sarkies MN, Bowles KA, Skinner EH, et al. Data collection methods in health services research: hospital length of stay and discharge destination. Appl Clin Inform 2015;6:96-109.

24. Charlson ME, Pompei P, Ales KL, et al. A new method of classifying prognostic comorbidity in longitudinal studies: development and validation. J Chronic Dis 1987;40:373-83.

25. Frenkel WJ, Jongerius EJ, Mandjes-van Uitert MJ, et al. Validation of the Charlson Comorbidity Index in acutely hospitalized elderly adults: a prospective cohort study. J Am Geriatr Soc 2014;62:342-6.

26. Vellas B, Villars H, Abellan G, et al. Overview of the MNA--Its history and challenges. J Nutr Health Aging 2006;10:456-63. Discussion 635.

27. Rubenstein LZ, Harker JO, Salvà A, et al. Screening for undernutrition in geriatric practice: developing the short-form mininutritional assessment (MNA-SF). J Gerontol A Biol Sci Med Sci 2001;56:M366-72.

28. Guigoz Y. The Mini Nutritional Assessment (MNA) review of the literature--What does it tell us? J Nutr Health Aging 2006;10:466-85. Discussion 85-7.

29. Sato K. Mini Nutritional Assessment Short-Form (MNA-SF) predicts clinical outcomes: cohort study of small-sized hospital in Japan. $J$ Gen Fam Med 2016;17:90-8.

30. Morin L, Vetrano DL, Rizzuto D, et al. Choosing Wisely? Measuring the burden of medications in older adults near the end of life: nationwide, longitudinal cohort study. Am J Med 2017; 130:927-36

31. Aoki T, Ikenoue T, Yamamoto $\mathrm{Y}$, et al. Attributes of primary care in relation to polypharmacy: a multicenter cross-sectional study in Japan. Int J Qual Health Care 2017;29:378-83.

32. Department of Community-Based Medical System, Graduate School of Biomedical and Health Sciences, Hiroshima University. http:// cbms.hiroshima-u.ac.jp/ (Cited 31 Oct 2018). 
33. Teixeira C, Ribeiro O, Fonseca AM, et al. Ethical decision making in intensive care units: a burnout risk factor? Results from a multicentre study conducted with physicians and nurses. J Med Ethics 2014;40:97-103.

34. Bernhardt BA, Silver R, Rushton $\mathrm{CH}$, et al. What keeps you up at night? Genetics professionals' distressing experiences in patient care. Genet Med 2010;12:289-97.

35. Matziou V, Vlahioti E, Perdikaris P, et al. Physician and nursing perceptions concerning interprofessional communication and collaboration. J Interprof Care 2014;28:526-33.
36. Kenison TC, Silverman P, Sustin M, et al. Differences between nurse practitioner and physician care providers on rates of secondary cancer screening and discussion of lifestyle changes among breast cancer survivors. J Cancer Surviv 2015;9:223-9.

37. Bowles D, McIntosh G, Hemrajani R, et al. Nurse-physician collaboration in an academic medical centre: The influence of organisational and individual factors. $J$ Interprof Care 2016;30:655-60.

38. Sollami A, Caricati L, Sarli L. Nurse-physician collaboration: a meta-analytical investigation of survey scores. J Interprof Care 2015;29:223-9. 